\title{
Venous air embolism in a patient with a massive upper gastrointestinal bleeding
}

\author{
Juan J Gonzalez, Ebrahim Abdelrazzak, Kavitha Kesari
}

Internal Medicine Residency Program, McLaren Health Care Corporation, Flint, Michigan, USA

\section{Correspondence to} Dr Juan J Gonzalez, dr.juanjose.gonzalez@gmail.com

Accepted 10 July 2018

\section{DESCRIPTION}

Emergency medical responders (EMS) were called in for a subject who developed multiple generalised tonic-clonic seizures attributed to hydrocodone-acetaminophen overdose and possible upper gastrointestinal (GI) bleeding. His medical history was significant for peptic ulcer disease status post partial gastrectomy, chronic alcoholism, polysubstance abuse, factor $\mathrm{V}$ Leiden mutation with recurrent deep venous thrombosis and pulmonary embolism on warfarin treatment. On his way to the hospital, EMS had difficulty obtaining an intravenous access, and was only successful after three attempts, and the patient was started on intravenous fluids and naloxone. In the emergency room he had an episode of massive bleeding per rectum and was haemodynamically unstable. Fluid resuscitation was started, second intravenous access was obtained and nasogastric tube was placed. CT of the chest, abdomen and pelvis without contrast (figure 1) demonstrated a small amount of air in the right atrium, main pulmonary artery, and right lower lobe segmental and subsegmental pulmonary arteries. He was placed on left lateral decubitus and given high-flow oxygen. Emergent transthoracic echocardiogram (TTE) showed ill-defined, radio-opaque densities in the right atrium, likely air embolism (figure 2). Left ventricular ejection fraction was estimated at $65 \%-70 \%$. There was no pericardial effusion. Abruptly, oxygen saturation dropped to $78 \%$. The patient was intubated, and emergent oesophagogastroduodenoscopy (EGD) revealed dark blood and clots in the oesophagus, as well as a small amount of bright red blood in the stomach with source of bleeding unidentified. There was no evidence of a fistulous tract. The patient was transferred to the medical intensive care unit, and intravenous pantoprazole was started. Repeat TTE reported no evidence of previous radio-opaque

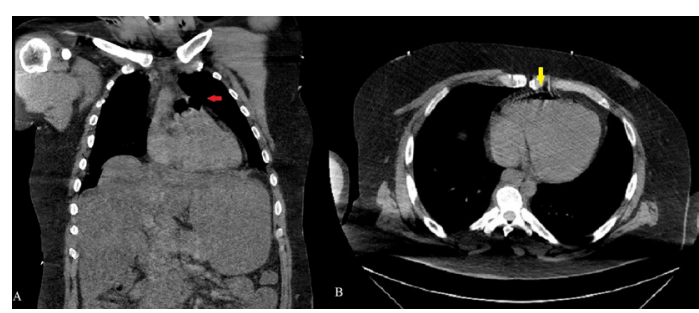

Figure $1 \mathrm{CT}$ of the chest, abdomen and pelvis without contrast. (A) Coronal view demonstrating two small bubbles of air in the pulmonary artery (red arrow). (B) Axial view showing a small amount of air in the right ventricle (yellow arrow).

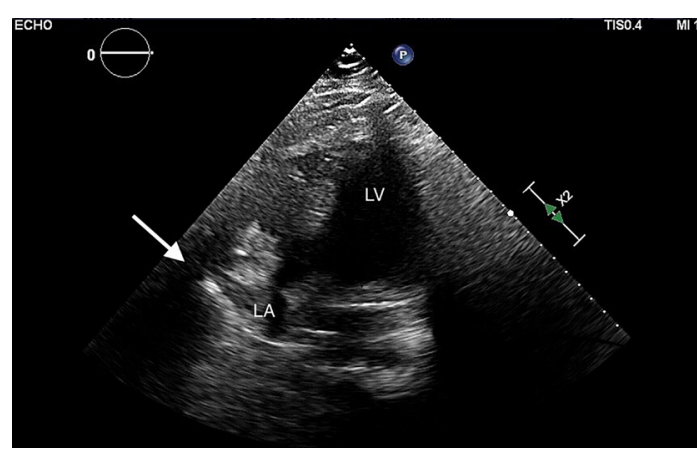

Figure 2 Transthoracic echocardiogram revealing ill-defined, radio-opaque densities in the right atrium, likely air embolism (white arrow). LA (left atrium); LV (left ventricle).

densities noted in the right atrium. The EGD revealed two gastric ulcers measuring $2 \times 1 \mathrm{~cm}$ with a clean base and $1 \times 1 \mathrm{~cm}$ covered with a clot, and epinephrine was injected and clips were placed. Due to recurrent GI bleeding, a second EGD was performed demonstrating shallow ulcers in the proximal oesophagus, three large gastric ulcers and fresh blood in the duodenum after dual therapy. Unfortunately, he developed multiorgan failure including hepatic, pulmonary and renal failure, fever complicated by disseminated intravascular coagulation, and persistent haemorrhagic shock. Despite aggressive measures including intravenous broad-spectrum antibiotics, fluid resuscitation, vasopressors and stress dose of intravenous corticosteroids, the patient died 20 days after admission.

Venous air embolism occurs when air enters the systemic venous circulation and travels to the right ventricle and pulmonary circulation. ${ }^{1}$ Generally air embolism is clinically asymptomatic, except for large air embolism $(>2-5 \mathrm{~m} / \mathrm{kg})$, which can rarely cause haemodynamic instability. ${ }^{2}$ Common causes include intravenous drug abuse, iatrogenic radiological or surgical procedures, trauma and positive pressure ventilation. ${ }^{3}$ In the index case, the most likely cause includes intravenous drug abuse or multiple intravenous access attempts. Immediate treatment is high-flow oxygen, mechanical ventilation, volume resuscitation and left lateral decubitus. ${ }^{2}$ This is imperative to prevent air trapping and decrease air embolus size. ${ }^{1}$ This case aims to highlight air embolism along severe volume depletion as a possible cause of right ventricular collapse leading to haemodynamic instability, and to take adequate measures to prevent this complication from medical procedures. 


\section{Learning points}

- High index of suspicion for air embolism should be included as a possible cause of cardiopulmonary instability in patients with recognised risk factors.

- Complications from medical, radiological and surgical interventions represent one of the most common causes of venous air embolism.

- Prompt treatment for air embolism including high-flow oxygen and left lateral decubitus is imperative to prevent air trapping and decrease air embolus size.

Acknowledgements We would like to thank cardiologist doctor Mustafa Hassan and the Radiology Department at McLaren Flint for their assistance in obtaining and interpreting the digital images.
Contributors JJG performed the literature review, and drafted, edited and finalised the manuscript. EA captured the images and edited and finalised the manuscript. KK edited and finalised the manuscript, and is the article guarantor.

Funding The authors have not declared a specific grant for this research from any funding agency in the public, commercial or not-for-profit sectors.

Competing interests None declared.

Patient consent Not required.

Provenance and peer review Not commissioned; externally peer reviewed.

\section{REFERENCES}

1 Jalota L, Aryal MR, Jain S. latrogenic venous air embolism from central femoral vein catheterisation. BMJ Case Rep 2013;2013.

2 Mirski MA, Lele AV, Fitzsimmons L, et al. Diagnosis and treatment of vascular air embolism. Anesthesiology 2007;106:164-77.

3 Bilello LA, Gacioch BQ, Phillips JP. Acute Cardiac Air Embolism. Clin Pract Cases Emerg Med 2018;2:101-2.

Copyright 2018 BMJ Publishing Group. All rights reserved. For permission to reuse any of this content visit http://group.bmj.com/group/rights-licensing/permissions.

BMJ Case Report Fellows may re-use this article for personal use and teaching without any further permission.

Become a Fellow of BMJ Case Reports today and you can:

- Submit as many cases as you like

- Enjoy fast sympathetic peer review and rapid publication of accepted articles

- Access all the published articles

- Re-use any of the published material for personal use and teaching without further permission

For information on Institutional Fellowships contact consortiasales@bmjgroup.com

Visit casereports.bmj.com for more articles like this and to become a Fellow 